\title{
When integration policies shape the impact of intergroup contact on threat perceptions: a multilevel study across 20 European countries
}

\section{Eva G. T. Green, Emilio Paolo Visintin, Oriane Sarrasin \& Miles Hewstone}

To cite this article: Eva G. T. Green, Emilio Paolo Visintin, Oriane Sarrasin \& Miles Hewstone (2019): When integration policies shape the impact of intergroup contact on threat perceptions: a multilevel study across 20 European countries, Journal of Ethnic and Migration Studies

To link to this article: https://doi.org/10.1080/1369183X.2018.1550159

View supplementary material $₫$

Published online: 22 Feb 2019.

Submit your article to this journal 지

View Crossmark data $₫$ 


\title{
When integration policies shape the impact of intergroup contact on threat perceptions: a multilevel study across 20 European countries
}

\author{
Eva G. T. Green ${ }^{a}$, Emilio Paolo Visintin ${ }^{a}$, Oriane Sarrasin ${ }^{a}$ and Miles Hewstone ${ }^{b, c}$ \\ anstitute of Psychology, University of Lausanne, Lausanne, Switzerland; ${ }^{b}$ Department of Experimental

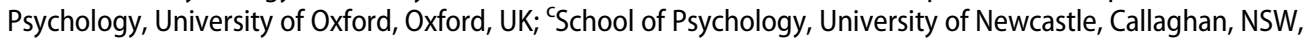 \\ Australia
}

\begin{abstract}
There is ample evidence of the beneficial effects of intergroup contact in reducing negative attitudes towards immigrants. Although the valuable role of institutional support, one of the initial optimal conditions for contact, has been demonstrated, the impact of actual immigration integration policies, as a manifestation of institutional support, remains unknown. In the current study, we examine how country-level migrant integration policies, assessed by the MIPEX indicator, shape the relationship between everyday contact and threat perceptions associated to immigration. Multilevel regression analyses were conducted with European Social Survey Round 7 data from 20 European countries ( $N=32,093$ citizens). Everyday contact was related to less symbolic and realistic threat perceptions. Moreover, on the country level, tolerant policies (a high MIPEX score) were related to higher everyday contact and lower symbolic threat perceptions. Confirming that institutional support facilitates the effects of contact, a cross-level interaction revealed that the link between everyday contact and symbolic threat was stronger in high rather than low MIPEX countries. The pattern of results was partially replicated when contact quality and cross-group friendships were assessed, though integration policies did not moderate the effects of these intergroup contact measures. These findings extend the body of multilevel contact research and are crucial for application as they show that integration policies have the potential to guide national majority members' perceptions regarding immigrants.
\end{abstract}

\section{KEYWORDS}

Intergroup contact; symbolic and realistic threat; ESS; MIPEX; multilevel; norms

\section{Introduction}

The number of immigrants living in European countries, whether from outside or within Europe, is at an all-time high. In 2016, there were over 35 million people born outside of the EU living in an EU country and over 19 million persons who had been born in a different EU country from the one where they were resident (Eurostat 2017). At the same time, immigration continues to assume prominence in political debates and election campaigns throughout Europe. Depicting the presence and arrival 
of immigrants as a threat to national majority population has gained rightwing populist movements and parties support over the last two decades across many European countries. Indeed, both realistic and symbolic threats have been associated with immigrants (e.g. Riek, Mania, and Gaertner 2006; Stephan and Renfro 2002). Realistic or material threat perceptions derive from anticipated competition between immigrants and the national majority for political power and for tangible, limited resources, such as jobs and housing as well as from suspicions that immigrants are taking unjustified advantage of welfare benefits and commit more crimes than the national majority. In a zero-sum conception, a gain for immigrants is a loss for the majority (Esses, Jackson, and Armstrong 1998). Symbolic threat, in turn, arises from supposed differences in culture and traditions as well as conflicting values, and is based on the fear of losing intangible resources. Immigrants are seen to challenge the worldview of the national majority. Threat perceptions - both realistic and symbolic - then foster prejudice towards and discrimination of immigrants (see Pereira, Vala, and Costa-Lopes 2010; Schlueter and Scheepers 2010).

Drawing on intergroup contact theory, we take a multilevel perspective simultaneously examining how everyday encounters with immigrants and country-level immigration integration policies influence the national majority members' threat perceptions associated to immigrants. There is ample evidence that intergroup contact relates to improved immigration attitudes, notably through reduced threat perceptions (e.g. Pettigrew et al. 2007). As institutional support plays a particularly important role in facilitating the beneficial effects of contact (Pettigrew and Tropp 2006), it should shape the impact of contact and individuals' attitudes towards immigration. Tolerant integration policies - representing institutional support - thus have the potential to both promote contact with immigrants and alleviate threat perceptions associated with immigration. In addition, tolerant policies should reinforce the threat-reducing effects of contact. Understanding these mechanisms is thereby crucial for furthering prejudice reduction and the maintenance of social cohesion. Regardless of policy coordination across Europe, in particular EU member states, countries vary in the measures they take to integrate immigrants such as access to nationality, civic political rights, labour market mobility, or anti-discrimination (Huddleston et al. 2017). Some countries are more, some less inclusive in their integration of immigrants. Implemented immigrant integration policies within a country convey its institutional stance concerning treatment of immigrants and provide normative cues to the national majority on appropriate ways of thinking about and encountering immigrants (e.g. Green and Staerklé 2013; Pettigrew et al. 2007). Thus the policy contexts in which individuals are embedded impact their attitudes towards immigration, notably their threat perceptions.

Despite the ostensible importance of support by institutions recognised from the outset of intergroup contact research, to our knowledge, there is no systematic evidence on the role of national integration policies to support this claim. With the European Social Survey ESS Round 7 data, the current paper provides a novel contribution by examining across 20 European countries how immigrant integration policies shape intergroup contact, symbolic and realistic threat perceptions as well as their relationship (see also Meuleman et al. 2019; for a broader conceptual model of the ESS module see Heath et al. 2019 introducing this Special Issue). 


\section{Intergroup contact and reduced threat perceptions}

Over 60 years of research has been inspired by the postulation that positive interactions with outgroup members engender prejudice reduction (Allport 1954; Hewstone and Swart 2011; Pettigrew and Tropp 2006). Confirming this core assumption of intergroup contact research, positive encounters with immigrants have been shown to alleviate anti-immigrant views through reduced symbolic and material threats that members of the national majority associate with immigration (e.g. Aberson 2015; Pettigrew et al. 2007; Tausch et al. 2007). Initially Allport (1954) suggested that equal status between groups, common goals, cooperation and institutional support were necessary conditions for contact to improve outgroup attitudes. Though a comprehensive meta-analysis has revealed that these conditions are not a prerequisite (Pettigrew and Tropp 2006), in particular two of these optimal conditions - equal status between groups and institutional support - are crucial when examining the threat-reducing effect of intergroup contact among immigrants and national majority members.

While immigrants may have a legal status allowing them to reside in the receiving country (though even this is not the case for so-called irregular immigrants), they do not have the same civic rights as those with citizenship. Moreover, differences in socio-economic status between immigrants and the national majority are commonplace. Such status differences can be detrimental for the development of cross-group friendships (Pettigrew, 1997), and thus close, high-quality contacts between the dominant, national majority members and subordinate immigrants can be difficult to achieve (see Dixon, Durrheim, and Tredoux 2005). Casual everyday interactions in the public sphere (e.g. in public transport, in the street, in local shops) favoured by cohabitation are, in turn, more frequent. For this reason, the current study focuses on the impact of everyday contacts on symbolic and material threat perceptions associated with immigration (for threat perceptions as antecedents of opposition to immigration e.g. Gorodzeisky and Semyonov 2019). Exposure to and mundane interactions with immigrants in everyday life can allow members of the majority to disconfirm the supposed threats. Though quality of contact (e.g. close and personal contact such as friendships) is particularly effective for reducing prejudice (e.g. Binder et al. 2009; Davies et al. 2011 for a meta-analysis), quantity of contact (i.e. frequency of encounters) also relates to reduced prejudice (Islam and Hewstone 1993; Voci and Hewstone 2003) and threat perceptions (Curseu, Stoop, and Schalk 2007; Tausch et al. 2007). Therefore, experiencing everyday interactions with immigrants should relate to reduced symbolic and material threat perceptions $(\mathrm{H} 1)$.

Yet, unlike the fairly straightforward positive appraisal of cross-group friendships, everyday encounters can be experienced as agreeable or disagreeable (for the distinction between positive and negative intergroup contact see, for example, Barlow et al. 2012). The appraisal of everyday contacts may also be influenced by other factors, notably norms. Indeed Allport $(1954,281)$ assumed that the effect of contact ' $\ldots$ is greatly enhanced if this contact is sanctioned by institutional supports (i.e. by law, custom, or local atmosphere)...'. Therefore when interpreting everyday interactions, people should be sensitive to the surrounding normative setting, defined by institutions. The meta-analysis by Pettigrew and Tropp (2006) suggests that, compared to other optimal conditions, institutional support is particularly important in facilitating the beneficial 
effects of intergroup contact. We examine how institutional support shapes everyday contact, perceptions of threat, as well as their relationship.

\section{Integration policies as institutional support}

The surrounding normative environment conveys appropriate ways to think about and deal with immigration (Crandall et al. 2002; Green and Staerklé 2013; Guimond, de la Sablonnière, and Nugier 2014; Pettigrew 2006). Normative information can take institutionalised forms reified and communicated through policies and legislation, by politicians, policy makers, and heads of organisations (e.g. companies, schools). Integration policies convey norms, or institutional support, that express governmental orientation and action toward cultural diversity in society, and thereby orient people's views regarding immigration (see also Schlueter et al. 2019). Countries differ in the way they deal with immigration, recognise immigrant minorities, and their level of inclusion and participation in society (e.g. Berry and Sam 2013; Bourhis et al. 1997). Guimond and colleagues (2013) showed that assimilationist vs. multiculturalist integration policies of countries affect perceived integration norms, which further influence attitudes towards these policies and immigrants in general. Indeed support for assimilation was related to negative immigration attitudes, whereas support for multiculturalism was related to positive immigration attitudes. This finding suggests that people are aware of and guided by integration policies. Prior multilevel research has demonstrated the impact of country-level policies on immigration attitudes. For example, in a study across 27 European countries, Schlueter, Meuleman, and Davidov (2013) found that tolerant integration policies, assessed with the Migrant Integration Policy Index (MIPEX www.mipex.eu; Huddleston et al. 2017), were related to reduced threat perceptions (see also Baur, Green, and Helbling 2016 for comparable relationships between regional-level integration policies, immigration attitudes and right-wing voting propensity in Switzerland). In a similar vein, Weldon (2006) found, across 15 European countries, that legislation defining citizenship in ethnic terms - involving for example shared ancestry requirements for citizenship - was related to intolerance toward immigrants and ethnic minorities. Therefore, in the current study, we expect less symbolic and material threat perceptions in countries with tolerant, rather than less tolerant, integration policies conveying institutional support (H2).

Whether integration policies encourage intergroup contact must also be considered. Tolerant integration policies can support encounters between national majority members and immigrants, whereas segregation policies, as an extreme example, set institutional barriers that curb contact. There is evidence of the impact of subjective perceptions of institutional support on interracial contact in educational settings (Pettigrew and Tropp 2011; for a recent example Tropp et al. 2016): when perceiving that teachers, school administrators or peers value positive intergroup relations, children and adolescents seek out interracial contact and develop more positive interracial attitudes (see however, Molina and Wittig 2006). The actual normative setting in which individuals are embedded has an impact too (see Christ et al. 2014; Sarrasin et al. 2012; van Assche et al. 2017). Although contact research has shown the valuable impact of institutional support, the impact of immigration integration policies has yet to be demonstrated. We expect that in countries with tolerant integration policies, more everyday contact with 
immigrants is sought (H3). Insofar as everyday contact is expected to predict reduced symbolic and material threat perceptions, tolerant integration policies should relate to reduced threat perceptions indirectly through increased everyday contact.

Moreover, in addition to direct effects, the moderating role of country-level integration policies has been evidenced previously. For example, Kauff and colleagues (2013) found with ESS Round 4 data from 23 countries that inclusive integration policies, assessed with MIPEX, reinforced the relationship between authoritarian ideologies and anti-immigration attitudes. The authors argued that individuals endorsing authoritarian ideologies feel threatened in settings with inclusive integration policies that conflict with their personal ideologies, which further heightens their negative stance towards immigration. Relatedly, Ariely (2012) examined the frequently evidenced positive relationship between national identification and anti-immigration attitudes. He found that lenient citizenship policies (tapped with both citizenship legislation and the Access to nationality sub-index of the MIPEX) reduced and even reversed the relationship between national identification and negative immigration attitudes (see also Pehrson, Vignoles, and Brown 2009; Visintin, Green, and Sarrasin, 2017).

Our focus here is on how integration policies shape the relationship between everyday contact and threat perceptions. Exposure to immigrants via everyday interactions should be interpreted more benevolently in tolerant and lenient than in intolerant and strict policy contexts (see also Kende, Phalet, et al. 2017). Based on Allport's (1954) key assumption that the effect of contact is enhanced when sanctioned by institutional support, we expect that in contexts with more tolerant integration policies, the negative relationships between everyday contact and symbolic and material threat perceptions will be reinforced (H4).

Evidence in support of this moderation hypothesis has been found, for example, in a contact intervention study aiming to improve anti-Roma attitudes among university students in Hungary where the contact intervention had a stronger prejudice-reducing effect when institutional norms were perceived as tolerant (Kende, Tropp, and Lantos 2017). To our knowledge the current study is the first to examine how institutional support in the form of country-level integration policies shapes both the level of everyday intergroup contact and its impact on perceived threat. Until now we have reasoned that experiences of everyday contact, which may be of mixed valence, are particularly prone to the surrounding normative context of which institutional support is one manifestation. While the focus of the current paper is on everyday intergroup contact, in additional analyses we also considered contact quality and intergroup friendships. Indeed, it is plausible that our argumentation around the role of institutional support extends to positive facets of intergroup contact. We test the four hypotheses enumerated above across 20 European countries for both symbolic and realistic threat perceptions, without a priori expectations concerning differences between the two forms of threat. ${ }^{1}$ The key concept and predictor of the current study, institutional support, is assessed through the MIPEX index.

\section{Method}

\section{Sample}

We used data from 20 out of the 21 countries participating in the European Social Survey ESS Round 7. Israel was excluded from the sample as it is not on the European continent 
and there is no MIPEX index for the country. We analyzed data of respondents who were over 18 years and held citizenship of the country of data collection. The final sample included 32,093 respondents $\left(52.9 \%\right.$ female, $\left.M_{\text {age }}=49.71, S D=17.75\right)$ after using listwise deletion of observations with missing values (for all the variables, missing values were less than $2 \%)$.

Table 1 presents descriptive statistics for symbolic and realistic threat perceptions, intergroup contact and the MIPEX index by country. We used design weights (dweight) for all descriptive and multilevel analyses.

\section{Symbolic threat, realistic threat and intergroup contact}

The dependent variables, symbolic threat and realistic threat, were measured by three items each. For symbolic threat, the questions were: 'Would you say that [country's] cultural life is generally undermined or enriched by people coming to live here from other countries?' (response scale ranging from 0 [cultural life undermined] to 10 [cultural life enriched]); 'Is [country] made a worse or a better place to live by people coming to live here from other countries?' $(0=$ worse place to live; $10=$ better place to live); 'Do you think the religious beliefs and practices in [country] are generally undermined or enriched by people coming to live here from other countries?' ( 0 = religious beliefs and practices undermined; $10=$ religious beliefs and practices enriched). Answers were reverse-coded so that higher values represent greater threat perceptions and averaged to create a 3item composite score of symbolic threat (Cronbach's $\alpha=.79$, as by country from .69 to $.85, M=4.81, S D=1.94)$.

Table 1. Number of respondents, MIPEX, mean scores (and standard deviations) of everyday contact, symbolic threat and realistic threat, and correlations of everyday contact with symbolic threat and with realistic threat, for each country under investigation.

\begin{tabular}{|c|c|c|c|c|c|c|c|}
\hline Country & $N$ & MIPEX & $\begin{array}{c}M(S D) \\
\text { Everyday } \\
\text { contact }\end{array}$ & $\begin{array}{c}M(S D) \\
\text { Symbolic } \\
\text { threat }\end{array}$ & $\begin{array}{c}M(S D) \\
\text { Realistic } \\
\text { threat }\end{array}$ & $\begin{array}{c}r \\
\text { Contact - } \\
\text { Symbolic threat }\end{array}$ & $\begin{array}{c}r \\
\text { Contact - } \\
\text { Realistic threat }\end{array}$ \\
\hline Austria AU & 1572 & 48 & $4.72(1.95)$ & $5.44(2.01)$ & $6.23(1.83)$ & $-.21^{* * *}$ & $-.15^{* * *}$ \\
\hline Belgium $\mathrm{BE}$ & 1521 & 70 & $4.75(2.04)$ & $5.01(1.75)$ & 6.06 (1.69) & $-.28^{* * *}$ & $-.16^{* * *}$ \\
\hline Czech Republic CZ & 1633 & 45 & $3.65(1.97)$ & $5.99(1.67)$ & $6.49(1.65)$ & -.04 & $-.07^{* *}$ \\
\hline Denmark DK & 1340 & 59 & $4.98(1.90)$ & 4.51 (1.99) & $5.41(1.56)$ & $-.16^{* * *}$ & $-.09^{* * *}$ \\
\hline Estonia EE & 1469 & 49 & $4.16(2.19)$ & $4.92(1.86)$ & $5.06(1.56)$ & $-.06^{*}$ & $-.10^{* * *}$ \\
\hline Finland FI & 1915 & 71 & 3.99 (1.92) & $3.91(1.74)$ & $5.49(1.52)$ & $-.25^{* * *}$ & $-.10^{* * *}$ \\
\hline France FR & 1703 & 54 & $4.76(2.00)$ & $5.18(2.00)$ & $5.59(1.66)$ & $-.24^{* * *}$ & $-.12^{* * *}$ \\
\hline Germany DE & 2714 & 63 & $5.09(1.93)$ & $4.34(1.86)$ & $5.29(1.54)$ & $-.18^{* * *}$ & $-.12^{* * *}$ \\
\hline Hungary HU & 1379 & 46 & $3.43(2.18)$ & $5.36(1.83)$ & $6.51(1.82)$ & $.06^{*}$ & -.03 \\
\hline Ireland IE & 2034 & 51 & $4.64(2.07)$ & $4.90(1.90)$ & $5.84(1.93)$ & $-.11^{* * *}$ & $-.08^{* * *}$ \\
\hline Lithuania LT & 1777 & 38 & $3.61(2.24)$ & $5.02(1.72)$ & $5.49(1.63)$ & $-.06^{*}$ & $-.07^{* *}$ \\
\hline Netherlands NL & 1677 & 61 & $4.96(1.87)$ & $4.60(1.52)$ & $5.78(1.42)$ & $-.19^{* * *}$ & $-.11^{* * *}$ \\
\hline Norway NO & 1256 & 69 & $5.25(1.77)$ & $4.60(1.83)$ & $5.35(1.40)$ & $-.12^{* * *}$ & -.05 \\
\hline Poland PL & 1414 & 43 & $2.18(1.74)$ & $4.43(1.76)$ & $5.48(1.66)$ & $-.16^{* * *}$ & $-.14^{* * *}$ \\
\hline Portugal PT & 1143 & 80 & $3.80(2.13)$ & $5.19(2.01)$ & $5.93(1.91)$ & $-.22^{* * *}$ & $-.11^{* * *}$ \\
\hline Slovenia SI & 1090 & 48 & $4.40(2.19)$ & $5.10(1.91)$ & $5.65(1.61)$ & $-.18^{* * *}$ & $-.12^{* * *}$ \\
\hline Spain ES & 1677 & 61 & $4.53(2.25)$ & $4.68(1.84)$ & $6.11(1.74)$ & $-.20^{* * *}$ & $-.13^{* * *}$ \\
\hline Sweden SE & 1608 & 80 & $5.86(1.53)$ & $3.48(1.81)$ & $4.73(1.60)$ & $-.21^{* * *}$ & $-.16^{* * *}$ \\
\hline Switzerland $\mathrm{CH}$ & 1157 & 46 & $4.94(1.86)$ & 4.53 (1.72) & $5.56(1.48)$ & $-.16^{* * *}$ & -.05 \\
\hline $\begin{array}{l}\text { United Kingdom } \\
\text { UK }\end{array}$ & 2014 & 56 & $5.12(1.88)$ & $5.38(2.20)$ & 5.72 (1.89) & $-.14^{* * *}$ & $-.06^{* *}$ \\
\hline
\end{tabular}

Note: Everyday contact ranged from 1 to 7 . Symbolic and realistic threat ranged from 0 to $10 .{ }^{*} p<.05 .{ }^{* *} p<.01$. ${ }^{* * *} p \leq .001$. 
For realistic threat, the questions were: 'Would you say that people who come to live here generally take jobs away from workers in [country], or generally help to create new jobs?' ( 0 = take away jobs; $10=$ create new jobs); 'Most people who come to live here work and pay taxes. They also use health and welfare services. On balance, do you think people who come here take out more than they put in or put in more than they take out?' $(0=$ generally take out more; $10=$ generally put in more $)$; 'Are [country]'s crime problems made worse or better by people coming to live here from other countries?' $(0=$ crime problems made worse $; 10=$ crime problems made better $)$. Answers were reverse coded so that higher values represent greater threat perceptions and a 3-item composite score of realistic threat was computed ( $\alpha=.71$, $\alpha$ s by country from .56 to $.82, M=5.68$, $S D=1.72)^{2}$

The key individual-level predictor of threat perceptions, quantity of everyday contact, was assessed with a single question 'How often do you have any contact with people who are of a different race or ethnic group from most [country] people when you are out? This could be on public transport, in the street, in shops or in the neighbourhood.' Response scale ranged from 1 (less than once a month) to 7 (every day) $(M=4.48$, $S D=2.14$ ).

In additional analyses contact quality and cross-group friendship measures were employed as indicators of positive contact. The quality of contact measure assessed the valence of [quantity of] contact, 'Thinking about this contact, in general how bad or good is it?' (from $0=$ extremely bad to $10=$ extremely good; $N=27,333, M=6.71 S D=$ 1.96). Note that the $N$ of analyses using contact quality was drastically reduced as this item was skipped in the interview for respondents who indicated having no contact. The question 'Do you have any close friends who are of a different race or ethnic group from most [country] people?' ( $1=$ Yes, several, $2=$ Yes, a few, $3=\mathrm{No}$, none at all, reverse-coded to denote positive contact; $N=32,046, M=2.38, S D=0.71$ ) assessed cross-group friendships. Given the item wording, however, the cross-group friendship measure can be considered to tap both contact quantity and quality.

\section{Individual-level controls}

To account for other antecedents of threat perceptions and contact, and for compositional differences across countries, we controlled for a number of individual-level characteristics, in addition to gender and age (Ceobanu and Escandell 2010). Respondents' subjective income was assessed with the question 'Which of the descriptions on this card comes closest to how you feel about your household's income nowadays?', with a response scale from 1 (living comfortably on present income) to 4 (finding it very difficult on present income). Answers were reverse coded so that higher values reflect higher subjective income $(M=3.11, S D=0.80)$. Respondents indicated their education in years $(M=13.11$ years, $S D=3.91$; range from 0 to 50 , with outlier values above the mean plus 3 standard deviations replaced by the cutoff value). They indicated their religiosity by answering the question 'Regardless of whether you belong to a particular religion, how religious would you say you are?' ( $0=$ not religious at all; $10=$ very religious $)$. On average, religiosity was moderate $(M=4.28, S D=3.02)$. For perceived diversity in the neighbourhood, we considered the question 'How would you describe the area where you currently live?' $(1=$ An area where almost nobody is of a different race or ethnic group from most [country] 
people; $3=$ Many people are of a different race or ethnic group) $(M=1.66, S D=0.68)$. Immigration background was assessed via place of birth of parents of respondents. If one or both parents were born abroad then the respondent was considered to have an immigration background (12.6\% of respondents).

Finally, due to the normative nature of integration policies, to ensure that their impact did not reflect compositional effects of individual-level conservative vs. progressive ideology, we considered the six-item Schwartz conservation value scale (Schwartz et al. 2001). ${ }^{3}$ Respondents assessed their resemblance $(1=$ very much like me $6=$ not at all like me $)$ with the following gender-matched descriptions of a fictitious person: 'It is important to her/ him to live in secure surroundings. She/he avoids anything that might endanger her safety', 'It is important to her/him that the government ensures her/his safety against all threats. She/he wants the state to be strong so it can defend its citizens', 'She/he believes that people should do what they're told. She/he thinks people should follow rules at all times, even when no-one is watching', 'It is important to her/him to be humble and modest. She/he tries not to draw attention to herself, 'It is important to her/him always to behave properly. She/he wants to avoid doing anything people would say is wrong', and 'Tradition is important to her/him. She/he tries to follow the customs handed down by her/his religion or her/his family'. Responses were reverse-coded and averaged to create a composite score of conservative values $(\alpha=.70$, as by country from .62 to .76, $M=4.34, S D=0.81)$.

\section{Country-level variables}

We used the 2014 Migrant Integration Policy Index (MIPEX, www.mipex.eu; Huddleston et al. 2017) to assess immigrant integration policies. MIPEX is a country-level index of immigrant integration policies that simultaneously considers 167 policy indicators from eight policy domains (i.e. healthcare, education, political participation, labour market mobility, anti-discrimination laws, permanent residence, access to nationality, family reunion). The index ranges from 0 (exclusive) to 100 (inclusive).

In addition to MIPEX, we controlled for other country-level characteristics known to shape immigration attitudes. Past multilevel research has demonstrated different effects of immigrant presence: On the one hand, there is evidence that immigrant presence provides contact opportunities, thereby improving people's attitudes towards immigration, on the other hand immigrant presence has been shown to relate to exclusionary immigration attitudes (see Pottie-Sherman and Wilkes 2015 for a meta-analysis). To account for the presence of immigrants, we controlled for country-level immigrant ratio and immigrant ratio change. To tap into immigration from non-EU and low-income countries, typically debated in Western receiving countries, we considered immigrant ratios of 2015 (based on United Nations, 2017) excluding immigrants coming from high-income Organization for Economic Cooperation and Development (OECD) countries. The immigrant ratio change score was calculated by subtracting the 2010 immigrant ratio from the 2015 immigrant ratio.

Insofar as economic scarcity has been related to people's anti-immigrant attitudes (Scheepers, Gijsberts, and Coenders 2002), we also controlled for country-level economic well-being with unemployment rate and the Gini index, which measures inequality in the distribution of income (data based on the Central Intelligence Agency, 2017). 
For the estimation of interaction terms, country-level predictors were grand-mean centred.

\section{Results}

Both symbolic and realistic threat perceptions as well as everyday intergroup contact varied significantly between countries (ICCs $=.081, .064$, and .139 respectively; countrylevel residual variance in intercept-only models, symbolic threat $=0.303, S E=0.106, p$ $=.004$ and realistic threat $=0.189, S E=0.058, p=.001$ : everyday intergroup contact $=$ $0.641, S E=0.251, p=.011)$. A multilevel approach simultaneously testing the impact of individual- and contextual-level predictors was thus indicated (Hox 2010). We performed multilevel regression analyses using maximum likelihood estimations with robust standard errors MLR (Mplus 6), and first included variables in the model step by step. As cross-level interactions were modelled, when used as a predictor, intergroup contact was centred at the group mean (Enders and Tofighi 2007). Supplemental online Tables 1-3 present the step-by-step model building including the model fits (bottom panel of tables) and regression coefficients for individual and country-level predictors (top panel of tables) for symbolic threat, realistic threat and intergroup contact respectively. To test our hypotheses, in Table 2 we summarise the findings for the three variables in models including the main predictors and the control variables (see table note for symbolic threat - everyday contact random slope).

Confirming the threat-reducing effects of intergroup contact (H1), everyday contact was associated with both lower symbolic and lower realistic threat perceptions. The correlation patterns in 19 of the 20 countries studied are in line with this finding (see Table 1; in Hungary the link between contact and symbolic threat perceptions was positive). In support of the hypothesis that institutional support alleviates feelings of threat $(\mathrm{H} 2)$,

Table 2. Final multilevel models for symbolic and realistic threat and intergroup contact (unstandardised regression coefficients, standard errors in parentheses).

\begin{tabular}{|c|c|c|c|}
\hline & $\begin{array}{c}\text { Symbolic threat }{ }^{\text {a }} \\
\text { Est. (SE) }\end{array}$ & $\begin{array}{l}\text { Realistic threat } \\
\text { Est. (SE) }\end{array}$ & $\begin{array}{c}\text { Intergroup contact } \\
\text { Est. (SE) }\end{array}$ \\
\hline Intercept & $5.81(0.24)^{* * *}$ & $7.00(0.17)^{* * *}$ & $3.40(0.34)^{* * *}$ \\
\hline \multicolumn{4}{|l|}{ Main predictors } \\
\hline Intergroup contact & $-0.08(0.01)^{* * *}$ & $-0.05(0.01)^{* * *}$ & - \\
\hline MIPEX & $-0.02(0.01)^{*}$ & $-0.01(0.01)$ & $0.03(0.005)^{* * *}$ \\
\hline Contact x MIPEX & $-0.003(0.001)^{* *}$ & - & - \\
\hline \multicolumn{4}{|l|}{ Individual level controls } \\
\hline Age & $0.002(0.002)$ & $-0.002(0.001)$ & $-0.02(0.002)^{* * * *}$ \\
\hline Gender $($ Male $=1$, Female $=0)$ & $0.04(0.04)$ & $-0.06(0.04)$ & $0.02(0.03)$ \\
\hline Years of education & $-0.10(0.01)^{* * *}$ & $-0.07(0.005)^{* * *}$ & $0.07(0.005)^{* * *}$ \\
\hline Immigration background & $-0.46(0.08)^{* * *}$ & $-0.42(0.08)^{* * *}$ & $0.26(0.08)^{* * *}$ \\
\hline Subjective income & $-0.26(0.03)^{* * *}$ & $-0.26(0.02)^{* * *}$ & $0.09(0.02) * * *$ \\
\hline Religiosity & $-0.04(0.01)^{* * *}$ & $-0.04(0.005)^{* * *}$ & $-0.01(0.01)$ \\
\hline Conservative values & $0.31(0.03)^{* * *}$ & $0.20(0.03)^{* * *}$ & $-0.11(0.02) * * *$ \\
\hline Diversity in neighbourhood & $-0.02(0.03)$ & $0.004(0.02)$ & $0.86(0.08)^{* * *}$ \\
\hline \multicolumn{4}{|l|}{ Country-level controls } \\
\hline Unemployment & $-0.02(0.01)$ & $0.02(0.02)$ & $-0.02(0.02)$ \\
\hline Gini & $0.003(0.02)$ & $-0.03(0.02)$ & $-0.03(0.02)$ \\
\hline Immigrant ratio & $-0.01(0.04)$ & $-0.002(0.03)$ & $0.13(0.03)^{* * *}$ \\
\hline Immigrant ratio $\Delta$ & $0.02(0.02)$ & $-0.03(0.01)^{*}$ & $-0.05(0.02)^{*}$ \\
\hline
\end{tabular}

${ }^{\mathrm{a}}$ Random slope (symbolic threat on contact) $=0.002(0.001), p=.04$.

${ }^{*} p<.05$. ${ }^{* *} p<.01$. ${ }^{* * *} p \leq .001$. 
symbolic threat perceptions were reduced in higher MIPEX countries. We did not, however, find significant evidence for this prediction for realistic threat.

Moreover, as hypothesised (H3), there were more experiences of everyday contact in higher MIPEX countries (note that as an outcome variable, everyday contact is not centred). This finding is in line with prior research demonstrating that institutional support fosters intergroup contact. No indirect effect through everyday contact to threat perceptions occurred, as these constructs are unrelated on the country level.

We also found support for Allport's (1954) initial argument that institutional support facilitates the effects of everyday contact (confirming H4). Indeed, a cross-level interaction between everyday contact and MIPEX predicting symbolic threat perceptions was found. The decomposition of the interaction showed that the negative association between intergroup contact and symbolic threat perceptions was stronger in countries with a high $\operatorname{MIPEX}(+1 S D, b=-0.11, S E=0.01, p<.001)$ than in countries with a low MIPEX $(-1$ $S D, b=-0.05, S E=0.02, p=.008$; see Figure 1). Figure 2 further depicts the correlation between everyday contact and symbolic threat by country as function of MIPEX. We did not find support for $\mathrm{H} 4$ for realistic threat (the relation between everyday contact and realistic threat did not vary across countries, therefore we did not pursue with testing cross-level interactions, see Model 3 in Supplemental online Table 2).

The individual-level control variables were also related to threat perceptions and contact. Conservation values were related to higher symbolic and realistic threat. Immigration background, higher education, subjective income as well as religiosity, in turn, were associated with less symbolic and material threat perceptions. Moreover, younger respondents, those holding less conservation values, with an immigration background, higher education, higher subjective income, and living in neighbourhood they considered diverse had more everyday contact.

None of the country-level controls were related to symbolic threat perceptions. In line with an intergroup contact rationale, realistic threat perceptions were reduced in countries with an increased immigration rate (note that this effect was not found in the step-by-step

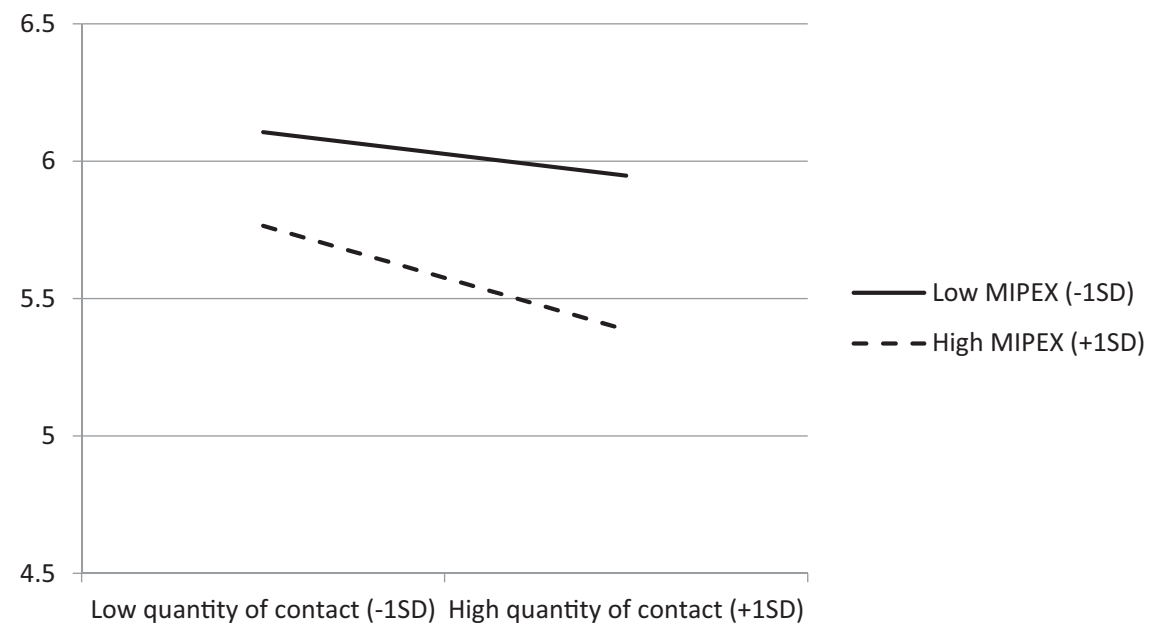

Figure 1. Decomposition of cross-level interaction: The relationship between everyday contact and symbolic threat as a function of MIPEX. 




Figure 2. Correlations between everyday contact and symbolic threat by MIPEX (See Table 1 for country codes).

model building reported in the Supplemental online Table 2). Moreover, supporting the intergroup contact reasoning that presence of immigrants provides opportunities for contact, everyday contact was greater in countries with high rather than low immigrant ratio (Wagner et al. 2006). However, supporting an intergroup threat approach (e.g. Scheepers, Gijsberts, and Coenders 2002 on ethnic competition theory) that increase in immigration fosters opposition to immigration, everyday contact was lower in countries that had experienced an increase in immigration. The Gini index and unemployment rate were unrelated to everyday contact. Importantly, inclusion of country-level controls in the models did not alter the effects of MIPEX and the cross-level interaction (see Supplemental online Table 1 Models $4 \mathrm{a}$ and $4 \mathrm{~b}$ for symbolic threat and Supplemental online Table 3 Models $2 \mathrm{a}$ and $2 \mathrm{~b}$ for everyday contact).

\section{Additional analyses}

In addition to integration policies predicting everyday contact and moderating its effects, it is plausible that they predict positive contact experiences and their effects. Thus, in additional analyses we reran the main models presented in Table 2 using both the quality of contact and cross-group friendship as the contact measure (ICCs $=.067$ and .058 respectively; country-level residual variance in intercept-only models: Quality of contact $=0.262, S E=0.111, p=.019$ and cross-group friendships $=0.029, S E=0.01$, $p=.001)$.

In support of $\mathrm{H} 1$, unsurprisingly, both contact quality and cross-group friendships were negatively related to symbolic $(b=-0.30, S E=0.01, p<.001 ; b=-0.43, S E=0.04, p<.001$ respectively) as well as realistic $(b=-0.22, S E=0.01, p<.001 ; b=-0.32, S E=0.04, p$ $<.001$ respectively) threat perceptions. As in the main analyses, MIPEX predicted symbolic threat perceptions (in line with $\mathrm{H} 2 ; b=-0.02, S E=0.01, p=.041 ; b=-0.02, S E=$ $0.01, p=.043$ respectively when contact quality and cross-group friendship were included as predictor in the model), but not realistic threat perceptions $(b=-0.01, S E=0.01, p$ $=.178 ; b=-0.01, S E=0.01, p=.129$ respectively). In addition, supporting $\mathrm{H} 3$, crossgroup friendships were more frequent in countries with tolerant integration policies $(b=0.004, S E=0.002, p=.007$; this was not the case for quality of contact, $b=0.01$, 
$S E=0.01, p=.350)$. The cross-level moderation hypothesis ( $\mathrm{H} 4)$ did not receive support in these additional analyses $(p s \geq .379)$.

\section{Discussion}

The main argument of this paper is that, by conveying tolerant ways of thinking about cultural diversity and immigration, inclusive integration policies foster everyday contact with immigrants, alleviate national majority members' associations of immigrationrelated threat, and reinforce the threat-reducing effect of everyday contact. Although prior research has shown that integration policies shape perceptions regarding immigration (Guimond et al. 2013; Kauff et al. 2013; Schlueter, Meuleman, and Davidov 2013), this paper provided a novel contribution by examining how policies shape the frequency of everyday contact and moderate the relationship between contact and anti-immigration attitudes, here threat perceptions. As predicted, we found that in countries with inclusive integration policies (i.e. a high MIPEX score) everyday encounters with immigrants were more frequent and subjective perceptions of symbolic (but not realistic) threat were lower. In addition, while contact was generally related to lower symbolic threat perceptions, the threat-reducing impact of everyday interactions was stronger in countries with relatively more inclusive integration policies than in countries with less inclusive policies (i.e. a lower MIPEX score).

These findings are important for intergroup contact theory, as we addressed the role of institutional support, the most crucial of the initial optimal conditions for contact outlined by Allport in 1954 (see Pettigrew and Tropp 2006), by means of country-level immigrant integration policies. Previously mainly the impact of subjective perceptions of institutional support has been studied, whereas our study suggests that the actual policy context has the power to facilitate contact and to reinforce the beneficial effects of contact. Beyond the impact of integration policies, these findings also suggest that more generally the normative setting in which individuals are embedded should be accounted for when examining immigration attitudes in survey research (Green and Staerklé 2013).

While on the individual-level everyday intergroup encounters predicted reduced realistic threat perceptions (e.g. seeing immigrants taking away jobs from natives), we found that immigrant integration policies were unrelated to realistic threat, and these policies did not moderate the relation between everyday intergroup contact and realistic threat perceptions. As the mean level of realistic threat perceptions was, if anything, slightly greater than that of symbolic threat, both types of threats are present in the minds of national majorities. It is possible that tolerant and inclusive policies address more adequately symbolic rather than material concerns. In fact, some of the domains of inclusiveness in integration policy, such as access to healthcare, may even trigger the very concerns composing realistic threat, fear of losing out on healthcare if immigrants are favoured over the national majority. This may explain why tolerant integration policies were unrelated to realistic threat perceptions.

Additional analyses were run with contact quality and cross-group friendship as contact measures. While the pattern of results was largely replicated, two differences must be noted. Tolerant policies were unrelated to increased contact quality, suggesting that contact quantity in broad terms (both frequency of everyday contact and number of cross-group friendships) is particularly sensitive to the surrounding normative 
context (here depicted with integration policies). Moreover, integration policies did not moderate the relation between contact quality or cross-group friendships and symbolic threat perceptions. Thus integration policies seem to reinforce the effect of superficial everyday contact, but not the effects of unequivocally positively appraised contact experiences, suggesting that such experiences are associated to reduced prejudice and threat perceptions irrespective of the normative climate. However, whether superficial everyday contact has a prejudice-reducing impact in the first place will depend on the appraisal of the interaction experience (Thomsen and Rafiqi 2017; see also Barlow et al., 2012, Study 1).

In the following paragraphs, we discuss some caveats concerning the results of the current study and offer suggestions for future research. First, while the reasoning of the paper was around encounters with immigrants and threat perceptions associated to immigration, the operationalisation of everyday contact referred to individuals of 'different race or ethnic group from most'. Despite this mismatch in the referred target groups, we assume, and the correlation patterns suggest, that in the context of the ESS immigration module, respondents associated both intergroup contact and threat questions to immigrants. Indeed, a study conducted in Germany (Asbrock et al., 2014) demonstrated that individuals tend to associate immigrant groups present both in their country and regions of residence when exposed to the generic notion of immigrant. Thus, while it is plausible that respondents had in mind immigrant groups present in their country when reporting on frequency of contact and perceptions of threat, the result patterns should be replicated in future research with measures with matching target groups.

Second, we examined the impact of a general exclusive vs. inclusive immigration policy indicator in reinforcing intergroup contact effects. A country may, however, be inclusive in some aspects (e.g. equal access to education) and exclusive in other aspects of integration policy (e.g. insufficient anti-discrimination legislation). Future research should match policy content and attitudinal outcomes, for example by examining how existing anti-discrimination legislation affects the relationship between intergroup contact experiences and individuals' support for anti-racism laws. Importantly, further understanding of how actual implementation of policy, such as anti-discrimination legislation, affects attitudes towards immigration is needed. This will allow evidence-based planning of effective interventions to reduce prejudice and discrimination on a more local level.

Third, in the current study we focused on the perspective of national majorities, the citizens of the country of data collection. Monitoring how integration policies shape the intergroup contact experiences with national majorities among immigrant minorities would be a fruitful future research avenue. Recent research on the so-called 'sedative' effects of contact has argued that when ethnic minorities have positive contact experiences with the dominant majority, they are less likely to endorse social change (Saguy et al. 2009). However, integration policies may play a role in this process such that inclusive integration policies counteract possible demobilising effects of positive contact. The recent work of Kauff and colleagues (2016), using notably ESS Round 1 data, point in the direction of this argument: national majorities' contact experiences on the country and local level - a manifestation of a supportive local atmosphere (akin to institutional support) - were related to ethnic minority members' endorsement of ingroup rights. Thus the normative setting had a mobilising rather than a demobilising effect. 
Finally, as in all cross-sectional studies firm causal claims are unwarranted. Yet the impact of intergroup contact on attitudes has been evidenced in experimental and longitudinal research (e.g. Binder et al. 2009; Swart et al. 2011). Public policies, such as inclusive or exclusive integration policies, reflect the stance of both respective institutions, and also individuals to the extent that citizens participate in policy making by electing representatives. Thus the relationship between migration policies and attitudes must be seen as mutually reinforcing rather unidirectional (e.g. Gundelach and Manatschal 2017). Indeed, the examination of micro-macro relations, for example whether individual political attitudes predict immigration policy on the contextual level, would be a fascinating research endeavour (see Christ et al. 2017; Green et al. 2016).

These limitations aside, the current study provided a novel contribution to the literature on immigration attitudes by demonstrating the role of immigration integration policy for intergroup contact and threat perceptions. Crucially, this study highlights the responsibility of policymakers in creating and maintaining tolerant and cohesive, multicultural societies.

\section{Notes}

1. Our approach is exploratory concerning eventual differences between the two forms of threat as prior research has found that effects of contact are similar (Aberson and Gaffney 2009; Tausch et al. 2007) or absent (Velasco Gonzaléz et al. 2008) for both, and in some cases stronger for symbolic (Curseu, Stoop, and Schalk 2007; Tausch, Hewstone, and Roy 2009), while in other cases stronger for material threat perceptions (Pereira et al. 2010).

2. Equivalence of measurement testing - ensuring that eventual differences in measurement would not bias substantive conclusions - was performed prior to the creation of these composite scores. Partial scalar invariance was reached (Satorra-Bentler corrected $\chi^{2}(254)=$ $1411.11, p<.001$; CFI $=.942$, RMSEA =.072). Note that the intercepts for the 'crime' and 'country worse place to live' items were allowed to vary in a set of countries. In addition, errors for two symbolic threat items were allowed to correlate.

3. High numbers of missing values $(2.26 \%-25.40 \%)$ and the cross-national differences in meaning precluded the use of the left-right political orientation continuum.

\section{Disclosure statement}

No potential conflict of interest was reported by the authors.

\section{Funding}

This work was supported by the Swiss National Science Foundation [Division 1 grant number 100014_159336 and National Center of Competence in Research nccr - on the move grant number 51NF40-142020].

\section{References}

Aberson, Christopher L. 2015. "Positive Intergroup Contact, Negative Intergroup Contact, and Threat as Predictors of Cognitive and Affective Dimensions of Prejudice." Group Processes \& Intergroup Relations 18 (6): 743-760.

Aberson, Christopher L., and Amber M. Gaffney. 2009. "An Integrated Threat Model of Explicit and Implicit Attitudes." European Journal of Social Psychology 39 (5): 808-830. 
Agency, Central Intelligence. 2017. “The World Factbook.” Accessed 23 May. https://www.cia.gov/ library/publications/the-world-factbook/.

Allport, Gordon W. 1954. The Nature of Prejudice. New York, NY: Addison-Wesley.

Ariely, Gal. 2012. "Do Those Who Identify with Their Nation Always Dislike Immigrants? An Examination of Citizenship Policy Effects." Nationalism and Ethnic Politics 18 (2): 242-261.

Asbrock, Frank, Gunnar Lemmer, Julia C Becker, Jeffrey Koller, and Ulrich Wagner. 2014. "Who are These Foreigners Anyway?' The Content of the Term Foreigner and its Impact on Prejudice." Sage Open 4 (2). 2158244014532819.

Barlow, Fiona Kate, Stefania Paolini, Anne Pedersen, Matthew J Hornsey, Helena RM Radke, Jake Harwood, Mark Rubin, and Chris G Sibley. 2012. "The Contact Caveat: Negative Contact Predicts Increased Prejudice More Than Positive Contact Predicts Reduced Prejudice." Personality and Social Psychology Bulletin 38 (12): 1629-1643.

Baur, Robert, Eva G. T. Green, and Marc Helbling. 2016. "Immigration-related Political Culture and Support for Radical Right Parties.” Journal of Ethnic and Migration Studies 42 (11): 1748-1773.

Berry, John W, and David L Sam. 2013. "Accommodating Cultural Diversity and Achieving Equity. An Introduction to Psychological Dimensions of Multiculturalism.” European Psychologist 18 (3): 151-157.

Binder, Jens, Hanna Zagefka, Rupert Brown, Friedrich Funke, Thomas Kessler, Amelie Mummendey, Annemie Maquil, Stephanie Demoulin, and Jacques-Philippe Leyens. 2009. "Does Contact Reduce Prejudice or Does Prejudice Reduce Contact? A Longitudinal Test of the Contact Hypothesis Among Majority and Minority Groups in Three European Countries." Journal of Personality and Social Psychology 96 (4): 843-856.

Bourhis, Richard Y, Lena Celine Moise, Stephane Perreault, and Sacha Senecal. 1997. "Towards an Interactive Acculturation Model: A Social Psychological Approach.” International Journal of Psychology 32 (6): 369-386.

Ceobanu, Alin M, and Xavier Escandell. 2010. "Comparative Analyses of Public Attitudes Toward Immigrants and Immigration Using Multinational Survey Data: A Review of Theories and Research.” Annual Review of Sociology 36: 309-328.

Christ, Oliver, Miles Hewstone, Katharina Schmid, Eva G. T. Green, Oriane Sarrasin, Mario Gollwitzer, and Ulrich Wagner. 2017. "Advanced Multilevel Modeling for a Science of Groups: A Short Primer on Multilevel Structural Equation Modeling." Group Dynamics: Theory, Research, and Practice 21 (3): 121-134.

Christ, Oliver, Katharina Schmid, Simon Lolliot, Hermann Swart, Dietlind Stolle, Nicole Tausch, Ananthi Al Ramiah, Ulrich Wagner, Steven Vertovec, and Miles Hewstone. 2014. "Contextual Effect of Positive Intergroup Contact on Outgroup Prejudice." Proceedings of the National Academy of Sciences 111 (11): 3996-4000.

Crandall, Christian S, Amy Eshleman, and Laurie O’brien. 2002. "Social Norms and the Expression and Suppression of Prejudice: The Struggle for Internalization." Journal of Personality and Social Psychology 82 (3): 359-378.

Curşeu, Petru Lucian, Ron Stoop, and René Schalk. 2007. "Prejudice Toward Immigrant Workers Among Dutch Employees: Integrated Threat Theory Revisited." European Journal of Social Psychology 37 (1): 125-140.

Davies, Kristin, Linda R Tropp, Arthur Aron, Thomas F Pettigrew, and Stephen C Wright. 2011. "Cross-group Friendships and Intergroup Attitudes: A Meta-analytic Review." Personality and Social Psychology Review 15 (4): 332-351.

Dixon, John, Kevin Durrheim, and Colin Tredoux. 2005. "Beyond the Optimal Contact Strategy: A Reality Check for the Contact Hypothesis.” American Psychologist 60 (7): 697-711.

Enders, Craig K, and Davood Tofighi. 2007. "Centering Predictor Variables in Cross-sectional Multilevel Models: A New Look at an Old Issue.” Psychological Methods 12 (2): 121-138.

Esses, Victoria M, Lynne M Jackson, and Tamara L Armstrong. 1998. "Intergroup Competition and Attitudes Toward Immigrants and Immigration: An Instrumental Model of Group Conflict." Journal of Social Issues 54 (4): 699-724.

Eurostat. 2017. “Migration and Migrant Population Statistics.” Accessed 23 May. http://ec.europa. eu/eurostat/statistics-explained/index.php/Migration_and_migrant_population_statistics. 
Gorodzeisky, Anastasia and Moshe Semyonov. 2019. "Perceptions and Misperceptions: Actual Size, Perceived Size and Opposition to Immigration in European Societies." Journal of Ethnic and Migration Studies. doi:10.1080/1369183X.2018.1550158.

Green, Eva G. T., Oriane Sarrasin, Robert Baur, and Nicole Fasel. 2016. "From Stigmatized Immigrants to Radical Right Voting: A Multilevel Study on the Role of Threat and Contact." Political Psychology 37 (4): 465-480.

Green, Eva G. T., and Christian Staerklé. 2013. "Migration and Multiculturalism." In Oxford Handbook of Political Psychology, edited by Leonie Huddy, David O. Sears, and Jack S. Levy, 852-889. Oxford: Oxford University Press.

Guimond, Serge, Richard J Crisp, Pierre De Oliveira, Rodolphe Kamiejski, Nour Kteily, Beate Kuepper, Richard N Lalonde, Shana Levin, Felicia Pratto, and Francine Tougas. 2013. "Diversity Policy, Social Dominance, and Intergroup Relations: Predicting Prejudice in Changing Social and Political Contexts." Journal of Personality and Social Psychology 104 (6): 941-958.

Guimond, Serge, Roxane de la Sablonnière, and Armelle Nugier. 2014. "Living in a Multicultural World: Intergroup Ideologies and the Societal Context of Intergroup Relations." European Review of Social Psychology 25 (1): 142-188.

Gundelach, Birte, and Anita Manatschal. 2017. "Ethnic Diversity, Social Trust and the Moderating Role of Subnational Integration Policy.” Political Studies 65 (2): 413-431.

Heath, Anthony, Eldad Davidov, Robert Ford, Eva G. T. Green, Alice Ramos, and Peter Schmidt. 2019. "Contested Terrain: Explaining Divergent Patterns of Public Opinion Towards Immigration Within Europe." Journal of Ethnic and Migration Studies. doi:10.1080/1369183X. 2019.1550145.

Hewstone, Miles, and Hermann Swart. 2011. "Fifty-odd Years of Inter-Group Contact: From Hypothesis to Integrated Theory." British Journal of Social Psychology 50 (3): 374-386.

Hox, Joop J. 2010. Multilevel Analysis: Techniques and Applications. New York, NY: Routledge.

Huddleston, Thomas, Özge Bilgili, Anne-Linde Joki, and Zvezda Vankova. 2017. "Migrant Integration Policy Index 2015.” Migration Policy Group, Accessed 23 May. http://www.mipex.eu/.

Islam, Mir Rabiul, and Miles Hewstone. 1993. "Dimensions of Contact as Predictors of Intergroup Anxiety, Perceived Out-group Variability, and Out-group Attitude: An Integrative Model.” Personality and Social Psychology Bulletin 19 (6): 700-710.

Kauff, Mathias, Frank Asbrock, Stefan Thörner, and Ulrich Wagner. 2013. "Side Effects of Multiculturalism the Interaction Effect of a Multicultural Ideology and Authoritarianism on Prejudice and Diversity Beliefs." Personality and Social Psychology Bulletin 39 (3): 305-320.

Kauff, Mathias, Eva G. T. Green, Katharina Schmid, Miles Hewstone, and Oliver Christ. 2016. "Effects of Majority Members' Positive Intergroup Contact on Minority Members' Support for Ingroup Rights: Mobilizing or Demobilizing Effects?” European Journal of Social Psychology 46 (7): 833-839.

Kende, Judit, Karen Phalet, Wim Van den Noortgate, Aycan Kara, and Ronald Fischer. 2017. "Equality Revisited: A Cultural Meta-analysis of Intergroup Contact and Prejudice." Social Psychological and Personality Science. doi:10.1177/1948550617728993.

Kende, Anna, Linda Tropp, and Nóra Anna Lantos. 2017. “Testing a Contact Intervention Based on Intergroup Friendship between Roma and Non-Roma Hungarians: Reducing Bias Through Institutional Support in a Non-Supportive Societal Context." Journal of Applied Social Psychology 47 (1): 47-55.

Meuleman, Bart, Koen Abts, Peter Schmidt, Thomas F. Pettigrew, and Eldad Davidov. 2019. "Economic Conditions, Group Relative Deprivation and Ethnic Threat Perceptions: A Crossnational Perspective." Journal of Ethnic and Migration Studies. doi:10.1080/1369183X.2018. 1550157.

Molina, Ludwin E, and Michele A Wittig. 2006. "Relative Importance of Contact Conditions in Explaining Prejudice Reduction in a Classroom Context: Separate and Equal?" Journal of Social Issues 62 (3): 489-509.

Pehrson, Samuel, Vivian L Vignoles, and Rupert Brown. 2009. "National Identification and Antiimmigrant Prejudice: Individual and Contextual Effects of National Definitions." Social Psychology Quarterly 72 (1): 24-38. 
Pereira, Cícero, Jorge Vala, and Rui Costa-Lopes. 2010. "From Prejudice to Discrimination: The Legitimizing Role of Perceived Threat in Discrimination Against Immigrants." European Journal of Social Psychology 40 (7): 1231-1250.

Pettigrew, Thomas F. 1997. “Generalized Intergroup Contact Effects on Prejudice." Personality and Social Psychology Bulletin 23 (2): 173-185.

Pettigrew, Thomas F. 2006. “The Advantages of Multilevel Approaches." Journal of Social Issues 62 (3): 615-620.

Pettigrew, Thomas F, Oliver Christ, Ulrich Wagner, and Jost Stellmacher. 2007. "Direct and Indirect Intergroup Contact Effects on Prejudice: A Normative Interpretation.” International Journal of Intercultural Relations 31 (4): 411-425.

Pettigrew, Thomas F, and Linda R Tropp. 2006. "A Meta-analytic Test of Intergroup Contact Theory." Journal of Personality and Social Psychology 90 (5): 751-783.

Pettigrew, Thomas F, and Linda R Tropp. 2011. When Groups Meet: The Dynamics of Intergroup Contact. New York: Psychology Press.

Pottie-Sherman, Yolande, and Rima Wilkes. 2015. "Does Size Really Matter? On the Relationship between Immigrant Group Size and Anti-Immigrant Prejudice.” International Migration Review 51 (1): 218-250.

Riek, Blake M, Eric W Mania, and Samuel L Gaertner. 2006. "Intergroup Threat and Outgroup Attitudes: A Meta-analytic Review." Personality and Social Psychology Review 10 (4): 336-353.

Saguy, Tamar, Nicole Tausch, John F Dovidio, and Felicia Pratto. 2009. "The Irony of Harmony: Intergroup Contact Can Produce False Expectations for Equality.” Psychological Science 20 (1): 114-121.

Sarrasin, Oriane, Eva G. T. Green, Nicole Fasel, Oliver Christ, Christian Staerklé, and Alain Clémence. 2012. "Opposition to Antiracism Laws Across Swiss Municipalities: A Multilevel Analysis.” Political Psychology 33 (5): 659-681.

Scheepers, Peer, Mérove Gijsberts, and Marcel Coenders. 2002. "Ethnic Exclusionism in European Countries. Public Opposition to Civil Rights for Legal Migrants as a Response to Perceived Ethnic Threat." European Sociological Review 18 (1): 17-34.

Schlueter, Elmar, Anu Masso, and Eldad Davidov. 2019. "What Factors Explain Anti-Muslim Prejudice? An Assessment of the Effects of Muslim Population Size, Institutional Characteristics and Immigration-related Media Claims." Journal of Ethnic and Migration Studies. doi:10.1080/1369183X.2018.1550160.

Schlueter, Elmar, Bart Meuleman, and Eldad Davidov. 2013. "Immigrant Integration Policies and Perceived Group Threat: A Multilevel Study of 27 Western and Eastern European Countries." Social Science Research 42 (3): 670-682.

Schlueter, Elmar, and Peer Scheepers. 2010. “The Relationship between Outgroup Size and Antioutgroup Attitudes: A Theoretical Synthesis and Empirical Test of Group Threat-and Intergroup Contact Theory." Social Science Research 39 (2): 285-295.

Schwartz, Shalom H, Gila Melech, Arielle Lehmann, Steven Burgess, Mari Harris, and Vicki Owens. 2001. "Extending the Cross-cultural Validity of the Theory of Basic Human Values with a Different Method of Measurement." Journal of Cross-Cultural Psychology 32 (5): 519-542.

Stephan, Walter G, and C. Lausanne Renfro. 2002. “The Role of Threat in Intergroup Relations.” In From Prejudice to Intergroup Emotions: Differentiated Reactions to Social Groups, edited by Diane M Mackie, and Walter G Stephan, 191-207. New York: Psychology Press.

Swart, Hermann, Miles Hewstone, Oliver Christ, and Alberto Voci. 2011. "Affective Mediators of Intergroup Contact: A Three-wave Longitudinal Study in South Africa." Journal of Personality and Social Psychology 101 (6): 1221-1238.

Tausch, Nicole, Miles Hewstone, Jared Kenworthy, Ed Cairns, and Oliver Christ. 2007. "CrossCommunity Contact, Perceived Status Differences, and Intergroup Attitudes in Northern Ireland: The Mediating Roles of Individual-Level Versus Group-Level Threats and the Moderating Role of Social Identification.” Political Psychology 28 (1): 53-68.

Tausch, Nicole, Miles Hewstone, and Ravneeta Roy. 2009. "The Relationships between Contact, Status and Prejudice: An Integrated Threat Theory Analysis of Hindu-Muslim Relations in India." Journal of Community \& Applied Social Psychology 19 (2): 83-94. 
Thomsen, Jens Peter Frølund, and Arzoo Rafiqi. 2017. "When Does Superficial Intergroup Contact Reduce Anti-foreigner Sentiment? Negative Contact as an Essential Condition.” International Journal of Comparative Sociology 59 (1): 25-43.

Tropp, Linda R, Thomas C O’Brien, Roberto González Gutierrez, Daniel Valdenegro, Katya Migacheva, Pablo Tezanos-Pinto, Christian Berger, and Oscar Cayul. 2016. "How School Norms, Peer Norms, and Discrimination Predict Interethnic Experiences Among Ethnic Minority and Majority Youth." Child Development 87 (5): 1436-1451.

United Nations, Department of Economic and Social Affairs, Population Division. 2017. "International Migrant Stock 2015." Accessed 23 May. http://www.un.org/en/development/ desa/population/migration/data/estimates2/estimates15.shtml.

Van Assche, Jasper, Arne Roets, and Alain Van Hiel. 2017. "The Mobilizing Effect of Right-Wing Ideological Climates: Cross-Level Interaction Effects on Different Types of Outgroup Attitudes.” Political Psychology 38 (5): 757-776.

Velasco González, Karina, Maykel Verkuyten, Jeroen Weesie, and Edwin Poppe. 2008. "Prejudice Towards Muslims in the Netherlands: Testing Integrated Threat Theory." British Journal of Social Psychology 47 (4): 667-685.

Visintin, Emilio Paolo, Eva G. T. Green, and Oriane Sarrasin. 2017. "Inclusive Normative Climates Strengthen the Relationship between Identification with Europe and Tolerant Immigration Attitudes: Evidence from 22 Countries." Journal of Cross-Cultural Psychology 49 (6): 908-923.

Voci, Alberto, and Miles Hewstone. 2003. "Intergroup Contact and Prejudice Toward Immigrants in Italy: The Mediational Role of Anxiety and the Moderational Role of Group Salience." Group Processes \& Intergroup Relations 6 (1): 37-54.

Wagner, Ulrich, Oliver Christ, Thomas F Pettigrew, Jost Stellmacher, and Carina Wolf. 2006. "Prejudice and Minority Proportion: Contact Instead of Threat Effects." Social Psychology Quarterly 69 (4): 380-390.

Weldon, Steven A. 2006. "The Institutional Context of Tolerance for Ethnic Minorities: A Comparative, Multilevel Analysis of Western Europe." American Journal of Political Science 50 (2): 331-349. 